\section{Reseña / Teoría y metodología de la extensión universitaria: el caso argentino}

López, M. L. (2020) Teoría y metodología de la extensión universitaria: el caso argentino. El Siku. ISBN: 978-987-26670-2-3

Sitio de descarga gratuita: https://cutt.ly/wiPe1wD

Por Mariana Natalia Villa

Universidad Nacional de Jujuy, Argentina

vmariana@gmail.com

(iD orcid.org/0000-0002-3939-2289
Sujetos y relaciones en extensión universitaria / Reseñas

다(1)(2)

El propósito de este libro es constituir un aporte para la construcción de un recorrido histórico, social y económico de las concepciones teóricas y metodológicas nacionales e internacionales sobre extensión universitaria con el fin de analizar e interpretar la relación entre la teoría y la práctica de extensión y, a su vez, la relación de esta con la investigación, la docencia y otros posicionamientos que han surgido en los cuatro primeros Congresos $\mathrm{Na}$ cionales de Extensión Universitaria de Argentina. Cabe señalar que, desde el punto de vista de su estructura, el libro cuenta con un índice, una introducción y cinco capítulos que poseen 207 referencias bibliográficas, 32 tablas y 36 imágenes, bibliografía y datos del autor, lo cual suma un total de 208 páginas.

En el primer capítulo el autor desarrolla los inicios y acontecimientos elementales de la extensión, los cuales se sitúan en contextos de actividades de educación y economía. A este respecto, propone reagrupar a todas las instituciones educativas que realizan extensión bajo la denominación de "extensión educativa" o "de nivel superior" para diferenciarla de la extensión rural. Puntualiza los sentidos que giran en torno al concepto "extensión" así como su relación con la docencia y la investigación universitaria y el modo en que se desarrolla en otros países, centrando su interés, no obstante, en el caso argentino. En síntesis, examina diez períodos correspondientes a momentos políticos, económicos, sociales y universitarios fundamentales que atravesó la extensión universitaria e identifica la relación extensión, universidad y entorno.

En el segundo capítulo señala dos enfoques que se imponen en el campo de la literatura sobre el tema. Así, se articulan dos conceptos denominados "extensión universitaria" y "vinculación tecnológica" como lógicas de la función extensionista. Se muestra en detalle que el enfoque extensionista (relación universidad, universitario y entorno) aparece en dos sentidos: el extensionismo asistencialista y el extensionismo crítico emancipatorio, vinculados ambos con los conceptos de interacción social y vinculación social; por su parte, el enfoque vinculacionista (relación universidad y sociedad) se subdivide en vinculacionista y neovinculacionismo. Ambos enfoques se enlazan con la actividad economicista y no economicista según las concepciones prácticas y teóricas de desarrollo social, sociedad y comunidad.

El siguiente capítulo describe la función de la extensión universitaria. En un panorama de crecimiento demográfico, de reestructuración y reconstrucción histórica, social y económica, detecta tres posicionamientos o enfoques subsidiarios: Responsabilidad Social Universitaria, desarrollo local y emprendedurismo, los cuales se vinculan a los procesos que 
impactan en los polos capital y trabajo. El autor plantea que la Responsabilidad Social Universitaria es un nombre alternativo para la extensión universitaria. Esta imposición del uso es una cuestión ideológica y de interés cuya legitimación e institucionalización se debe a varios factores institucionales y empresariales, y se considera una estrategia de conexión con la producción económica que impacta en las actividades organizacionales, educativas, cognitivas y sociales. En cuanto al emprendedurismo, se destaca un optimismo por la formación de mentalidades emprendedoras y una mirada negativa respecto del proceso que implica. Asimismo, describe cómo se relacionan la universidad y el emprendedurismo. De modo que a partir de la idea de universidades emprendedoras surge el concepto de incubadoras de empresas a través de varias fases. Su proceso de institucionalización se desarrolla gracias a las redes latinoamericanas y universitarias, por medio de varias leyes y su curricularización en carreras de grado y posgrado. El desarrollo local surge como respuesta a los procesos de globalización y de repensar el concepto de región y de las interacciones históricas y sociales. Su institucionalización se registra en Argentina mediante un decreto y en las universidades se observan dos tendencias orientadas por la economía social y el desarrollo sociocomunitario.

En el capítulo cuatro explica cómo se logra conocer y entender el estado de la teoría extensionista. Para ello, realiza relevamientos comparativos de la bibliografía. Estos datos corresponden a las producciones textuales vinculadas con las reflexiones, narraciones de experiencias y de investigación, teniendo en cuenta los tipos de publicaciones, países con mayor y menor producción escrita e indización sobre el tema. Destaca que la producción bibliográfica sobre la extensión universitaria tuvo altibajos y puntos de resignificación en los años 90. Permite apreciar el estado actual de la teoría como también su metodología y la calidad de la investigación que realizan los academicistas. Concluye con la sistematización de las prácticas metodológicas frecuentes que surgen en los Congresos Nacionales de Extensión Universitaria y con el concepto de demanda asociada a la idea de pedido y a la práctica de intervención extensionista.

El último capítulo analiza la importancia de los primeros cuatro Congresos Nacionales de Extensión Universitaria de Argentina. Estos acontecimientos constituyen los ejes que articulan el contenido del libro y un hito en la resignificación de la extensión universitaria. En estas líneas se enfoca en las categorías de análisis que se generan a raíz del arduo trabajo de cruce de datos provenientes de las producciones textuales ordenadas por temáticas. Identifica y describe detalladamente las temáticas relacionadas en mayor o menor medida con la función extensionista y los sujetos y objetos que intervienen en los debates teóricos y prácticos de las producciones. Analiza la bibliografía compartida por las diferentes temáticas, a las que denomina "redes bibliográficas" y los modos de vincularse con las funciones de las universidades: docencia e investigación. Además, destaca el gran impulso de las universidades públicas para proporcionar un lugar y un papel importante al objeto extensión universitaria. Por último, se anexa una tabla categorial.

Este libro se convierte así en una referencia fundamental para las personas interesadas en la temática de la extensión universitaria y, por lo tanto, es un valioso instrumento para académicos en busca de datos, revisión histórica, económica y social, y líneas de investigación del objeto extensión universitaria en Argentina. 